\title{
The Possibility of Minimizing Rutting Distress in Asphalt Concrete Wearing Course
}

\author{
Hanady M. Abd Al Kareem \\ Department of Civil Engineering \\ College of Engineering \\ University of Baghdad \\ Baghdad, Iraq \\ EnHanodaa@gmail.com
}

\author{
Amjad Hamad Khalil Albayati \\ Department of Civil Engineering \\ College of Engineering \\ University of Baghdad \\ Baghdad, Iraq \\ a.khali1@uobaghdad.edu.iq
}

\begin{abstract}
The excessive permanent deformation (rutting) in asphalt-concrete pavements resulting from frequent repetitions of heavy axle loads is studied in this paper. Rutting gradually develops with additional load applications and appears as longitudinal depressions in the wheel path. There are many causes of the rutting of asphalt roads, such as poor asphalt mixing and poor continuous aggregate gradation. All factors affecting the mixture resistance to permanent deformation must be discussed, and all must be properly considered to reduce the rutting propensity of asphalt-aggregate mixtures. In this study, several mixtures were produced with the most common techniques in rutting resistance (using the most effective additives for each mixture), and their performance was compared with the (conventional) mixture currently used in Iraq. The tests focused on the asphalt-concrete mixture for wearing courses. Different mixtures types were tried, namely, dense hot asphalt mixture (HMA) with two different asphalt contents $(4.7 \%$ and $5.3 \%)$, Open-Grade Friction Course (OGFC) mixture, Stone Mastic Asphalt (SMA) mixture, and Beton Bitumineux a Module Eleve (BBME). The modifiers included natural Sisal Fibers (SFs), Carbon Fibers (CFs), and mineral filler (hydrated lime, HL). Marshall test was carried out to find stability and flow values. Rutting was evaluated by the repeated load test for cylindrical specimens under two temperatures $\left(40^{\circ} \mathrm{C}\right.$ and $\left.60^{\circ} \mathrm{C}\right)$ to obtain the permanent deformation parameters. The parameters were used as input to the VESYS $5 \mathrm{~W}$ software to evaluate the rut depth during different times of design life under $7 \times 10^{\wedge} 6$ Equivalent Single Axle Loads (ESALs). The results of the selected mixtures were compared with the mixture designed in the laboratory dense gradation mix Job-Mix Formula (JMF)) within the limits of the Iraqi specification (SCRB,2003). Manipulation of the aggregate gradation that is customary in the implementation of the local mixture showed that the best performance regarding rutting resistance was exhibited by JMF, which decreased the rut depth at $40^{\circ} \mathrm{C}$ and $60^{\circ} \mathrm{C}$ by $21.63 \mathrm{~mm}$ and $44.304 \mathrm{~mm}$ respectively, in comparison with the conventional mixture. Changing the aggregate gradation of the local mixture gives better performance in rutting resistance without additives or changing the percentage of asphalt, at the same cost.
\end{abstract}

Keywords-rutting; HMA; SMA; OGFC; sisal fibers; carbon fibers; hydrated lime; Job Mix Formula; repeated load test; BBME; VESYS

\section{INTRODUCTION}

The term "permanent deformation" has been used to describe any distortion of a pavement surface, including shoving and pushing due to mix instability [1]. Today, this form of distress refers to the longitudinal depression or "ruts" that form in the wheel paths due to the consolidation and/or lateral movement in one or more of the component pavement layers due to repeated, transient load applications [1]. Because rutting appears only as a change in the transverse surface profile, it is often erroneously blamed on surface instability [2]. The rutting of asphalt roads has many causes, e.g. poor asphalt mix and poor aggregate gradations. All the factors affecting mixture resistance to permanent deformation must be properly considered in order to reduce the rutting propensity of asphaltaggregate mixtures. At the same time, it must be emphasized that the states of stress and strain caused by traffic loading also significantly influence pavement rutting [2]. In this study, different approaches are used to minimize the rutting distress in local asphalt concrete pavement structures, all of which concentrate on asphalt concrete mixtures for wearing courses. Different types of dense hot asphalt mixtures are used, which are considered the workhorse of HMA since they may be used effectively in all pavement layers for all traffic conditions [1, 2]. Dense-graded mixes are designed to resist all types of distresses developed from the applied stresses. These distresses include fatigue cracking, rutting, moisture damage, and thermal cracking. They are expected to minimize the service life and increase the maintenance costs [3].

Rutting is considered to be a major distress that frequently occurs in flexible pavements due to the nonlinear, viscous, and plastic behaviors of asphalt mixes [4]. Rutting on high volume roadways can be prevented if angular coarse and fine aggregates are used and if the air voids in the mixture do not fall below approximately 3.0\% [5]. A Stone-Mastic Asphalt (SMA) mixture is a gap-graded HMA that maximizes rutting resistance and durability with a stable stone-on-stone skeleton held together by a rich mixture of Asphalt Cement (AC), filler, and stabilizing agents, such as fibers and/or asphalt modifiers. The primary purpose of SMA mixes improves rut resistance and durability. Therefore, these mixes are almost exclusively used for surface courses on high volume interstates, and U.S. 
highways. Special cases such as heavy, slow-moving vehicles may warrant the use of SMA for intermediate and base layers [6]. The gradation of the aggregates is the largest element that affects the overall performance of the pavements when studying the rutting behavior of asphalt pavements [6, 7]. Open Graded Friction Course (OGFC) mixtures are designed to be permeable to water, which differentiates them from densegraded and SMA mixtures that are relatively impermeable. These mixtures use only crushed stone or, in some cases, crushed gravel with a small percentage of manufactured sand. OGFC mixtures reduce splash/spray from tires in wet weather and typically result in a smoother surface than dense-graded HMA [6]. Authors in [7] found that the result of permanent deformation of OGFC with Carbon Fibers (CFs) under repeated pressure levels of $0.068,0.138$, and $0.206 \mathrm{MPa}$ at $25^{\circ} \mathrm{C}$ decreased by $16.9,17.8$, and $10.1 \%$ when using CFs by $0.3 \%$ and a length of $2 \mathrm{~cm}$ at pressure levels of $0.068,0.138$, $0.206 \mathrm{MPa}$, respectively. With modified asphalt pavement, some ACs require modification to meet specifications. Modified AC usually has a higher initial cost than the unmodified $\mathrm{AC}$, but it provides a longer service life with less maintenance $[8, .9]$. The present research focuses on additives with effective performance on rutting resistance that are suitable for the selected mixtures. Fibers are currently being used extensively in porous asphalt friction courses more than polymers and other additives, with the primary purpose of increasing asphalt content without any drain down problems [10]. The fiber reinforces the binder system, thus causing an increase in its viscosity. The resulting mix has greater stability and possibly higher resistance to rutting and other distress than similar mixes without the addition of fibers. Mineral and natural fibers were used and their rutting behaviors were compared. Hydrated Lime (HL) is also used to improve HMA as mineral filler. It is an additive that increases pavement life and performance through multiple mechanisms [11].

Two types of fibers are used, man-made CF and Sisal (Agave Sisalana) Fibers (SFs). CF is a very strong lightweight synthetic fiber typically made by carbonizing acrylic fibers at high temperatures. CFs can be used as an additive to asphalt to make electrically conductive AC [12]. SFs are obtained by the removal of fiber bundles from dried sisal plant leaves growing in tropical environments. SFs have high strength and rigidity because of their high cellulose rate $(\sim \% 78-88)$. In addition, SFs have good elasticity due to their high moisture absorption capability because of their hollow structure and the large amount of hydroxyl groups in their chemical bonds. This ecofriendly fiber is also cheaper than synthetic fibers, which are used for technical textiles while it is a useable material for reinforcing dense graded pavement [13]. Additionally, mineral filler HL can be considered an alternative modifier to improve the properties of asphalt binders and mixtures. HL can significantly improve both moisture damage and rutting resistance. The application of Hin asphalt binders is an effective and economical method to improve the performance of asphalt mixtures to resist moisture damage and rutting. Several studies have shown the beneficial application of HL in asphalt mixtures to improve moisture susceptibility either by adding dry HL to wet aggregates or by adding lime slurry to dry aggregates $[14,15]$.
The road construction industry faces the challenge of designing and constructing high-performance asphalt materials to meet the ever-growing demand of increasing traffic volumes and axle loadings. EME (Enrobés à Module Elevé) or simply high-modulus asphalt was developed in France in the midseventies. EME is a high-performance material for use in heavy-duty pavements. EME for base courses and Beton Bitumineux a Module Eleve (BBME) for binders and wearing courses are called High-Modulus Asphalts (HiMAs). Two classes of EME and 3 classes of BBME are defined. EME class 2 and BBME class 3 are specified for the most heavily trafficked roads. They require higher binder contents according to aggregate gradation [16]. The Job Mix Formula (JMF) or dense gradation mix submittal is the mechanism to confirm that the produced mix is in accordance with the project specifications. The end result of a successful mix design is a recommended mixture of aggregates and asphalt binder. This recommended mixture also includes aggregate gradation and asphalt binder type asphalt binder content are specified based on the JMF along with the allowable specification bands for inherent material and production variability. These target values and specifications are based on the JMF and not any general HMA gradation requirements. Thus, the mix designer is free to choose a particular gradation for the JMF, and then the manufacturer is expected to adhere quite closely to this JMF gradation during production. The Iraqi standard specifications for roads and bridges, SCRB R/9, 2003, allowed the prepared JMF for asphalt mixtures to accommodate some tolerances with regard to the following properties: coarse aggregate gradation, fine aggregate gradation, filler content, AC content, and mixing temperature [17].

\section{MATERIALS}

Locally available materials were utilized in this study. AC 40-50 and AC 20-30 (for the BBME mixture only), aggregates (coarse, fine), and filler were used. SF, CF and HL were used as additives, and $6 \mathrm{AC}$ mixtures were prepared for wearing a course layer with 3 different asphalt contents, i.e. $4.7 \%, 5.3 \%$, and $6 \%$ depending on the type of mix, by the weight of the total mixture as shown in Tables I and II.

TABLE I. SELECTED AC OF THE MIXTURES

\begin{tabular}{|c|c|c|}
\hline Types of Mixture & Selected AC\% & Ref. \\
\hline Conventional HMA without additives & \multirow{2}{*}{4.7} & - \\
\cline { 1 - 1 } High-stiffness asphalt (EME) & & {$[37]$} \\
JMF & \multirow{2}{*}{5.3} & {$[38]$} \\
\hline SMA & & {$[32]$} \\
\hline Hot mix asphalt (HMA) & 6.0 & {$[40]$} \\
\hline OGFC
\end{tabular}

TABLE II. SELECTED MODIFIER CONTENT (\%)

\begin{tabular}{|c|c|c|c|}
\hline Modifier Types & Modifier content (\%) & Modifier's length (cm) & Ref. \\
\hline Carbon fiber (CF) & $0.3 \%$ & 1.5 & {$[38]$} \\
\hline Sisal fiber (SF) & $0.3 \%$ & 0.5 & {$[20]$} \\
\hline Hydrated lime (HL) & $1.5 \%$ & - & {$[41]$} \\
\hline
\end{tabular}

\section{A. Ashphalt Cement}

In this research project, the experimental work was carried out by using $\mathrm{AC}$ 40-50 and AC 20-30 penetration grade 
bitumen from the Daurah refinery. Table III shows the AC physical properties.

TABLE III. PHYSICAL PROPERTIES OF AC

\begin{tabular}{|c|c|c|c|c|c|}
\hline Test & $\begin{array}{c}\text { Test } \\
\text { condition }\end{array}$ & Units & $\begin{array}{c}\text { Asphalt } \\
\text { binder } \\
(\mathbf{2 0 - 3 0})\end{array}$ & $\begin{array}{c}\text { Asphalt } \\
\text { binder } \\
(\mathbf{2 0 - 3 0})\end{array}$ & $\begin{array}{c}\text { EME* }^{*} \\
\text { specification }\end{array}$ \\
\hline Penetration & $\begin{array}{c}100 \mathrm{~g}, 25^{\circ} \mathrm{C}, \\
5 \mathrm{~s}, 0.1 \mathrm{~mm}\end{array}$ & $1 / 10 \mathrm{~mm}$ & 24 & 24 & $20-30$ \\
\hline Ductility & $\begin{array}{c}25^{\circ} \mathrm{C}, \\
5 \mathrm{~cm} / \mathrm{min}\end{array}$ & $\mathrm{cm}$ & 18 & 18 & - \\
\hline Flash point & - & ${ }^{\circ} \mathrm{C}$ & 300 & 300 & $240 \mathrm{Min}$. \\
\hline $\begin{array}{c}\text { Softening } \\
\text { point }\end{array}$ & $(4 \pm 1)^{\circ} \mathrm{C} / \mathrm{min}$ & ${ }^{\circ} \mathrm{C}$ & 61.5 & 61.5 & $55-63$ \\
\hline $\begin{array}{c}\text { Specific } \\
\text { gravity }\end{array}$ & - & $\mathrm{g} / \mathrm{cm}^{3}$ & 1.03 & 1.053 & - \\
\hline $\begin{array}{c}\text { Penetration } \\
\text { index }\end{array}$ & -- & - & -0.27 & -0.27 & \begin{tabular}{c}
$+0.7 \mathrm{Max}$. \\
\hline $\begin{array}{c}\text { Retained } \\
\text { penetration. }\end{array}$
\end{tabular} \\
\hline $\begin{array}{c}\text { Change of } \\
\text { mass }\end{array}$ & $\%$ & 75 & 75 & $55 \mathrm{Min}$. \\
\hline $\begin{array}{c}\text { Retained } \\
\text { ductility }\end{array}$ & $5 \mathrm{~cm} / \mathrm{min}$ & ${ }^{\circ} \mathrm{cm}$ & 13 & 13 & $0.5 \mathrm{Max}$. \\
\hline $\begin{array}{c}\text { Softening } \\
\text { point }\end{array}$ & $(4 \pm 1)^{\circ} \mathrm{C} / \mathrm{min}$ & ${ }^{\circ} \mathrm{C}$ & 68.4 & 68.4 & - \\
\hline $\begin{array}{c}\text { Increased } \\
\text { softening } \\
\text { point }\end{array}$ & - & ${ }^{\circ} \mathrm{C}$ & 6.9 & 6.9 & $8 \mathrm{Max}$. \\
\hline
\end{tabular}

TABLE IV. PHYSICAL PROPERTIES OF THE AGGREGATES

\begin{tabular}{|c|c|c|c|}
\hline Laboratory test & $\begin{array}{c}\text { ASTM } \\
\text { designation }\end{array}$ & $\begin{array}{c}\text { Test } \\
\text { results }\end{array}$ & $\begin{array}{c}\text { SCRB } \\
\text { specification }\end{array}$ \\
\hline \multicolumn{4}{|c|}{ Course aggregates } \\
\hline $\begin{array}{c}\text { Apparent specific } \\
\text { gravity }\end{array}$ & C-127 & 2.687 & - \\
\hline Bulk specific gravity & C-127 & 2.61 & - \\
\hline Water absorption, \% & C-127 & 0.21 & - \\
\hline $\begin{array}{c}\text { Fractured pieces } \\
\text { angularity), } \%\end{array}$ & D-5821 & 96 & 90 Min \\
\hline $\begin{array}{c}\text { Percent wear (Los } \\
\text { Angeles, abrasion), \% }\end{array}$ & C-131 & 17.8 & 30 Max \\
\hline \multicolumn{4}{|c|}{ Fine aggregates } \\
\hline $\begin{array}{c}\text { Apparent specific } \\
\text { gravity }\end{array}$ & C-128 & 2.683 & - \\
\hline Bulk specific gravity & C-128 & 2.62 & - \\
\hline Water absorption, \% & C-128 & 0.4 & - \\
\hline
\end{tabular}

\section{B. Aggregates}

Coarse crushed aggregates were obtained from the AlNibaie quarry. The coarse aggregate size ranged between $12.5 \mathrm{~mm}$ and the No. 4 sieve $(4.75 \mathrm{~mm})$. Fine aggregates were bought from a local source. Laboratory evaluation described the basic properties of the aggregates. The results are presented in Table IV according to the specification limit (SCRB, 2003) [17]. For HMA and JMF, aggregate gradation was selected according to [17], with a nominal maximum size of $12.5 \mathrm{~mm}$, (wearing course type IIIA). OGFC gradation was selected according to the ASTM7064 specification [18]. The nominal maximum size of the aggregates is $12.5 \mathrm{~mm}$. The SMA gradation selected in this study follows the AASHTO [19]. Table V and Figures 1-3 show the selected aggregate gradation. EME samples shall be designated as EME 0/10, EME 0/14, and EME $0 / 20$, and BBME samples shall be designated as BBME
$0 / 10$ or BBME $0 / 14$ according to their aggregate size [16]. The target grading should fall within the appropriate limits explained in Table IX [20]. For the purposes of this work, the appropriate grading for the wearing course based on [17] is BBME 0/14. The selected gradations with the specification limits of BBME 0/14 are tabulated in Table VI and Figure 4.

TABLE V. SELECTED AGGREGATE GRADATION

\begin{tabular}{|c|c|c|c|c|c|c|c|}
\hline \multirow{2}{*}{$\begin{array}{c}\text { Sieve } \\
\text { size }\end{array}$} & \multicolumn{4}{|c|}{ Passing by weight (\%) } & \multicolumn{3}{c|}{ Specification range } \\
\cline { 2 - 8 } & \multicolumn{3}{|c|}{ Selected gradation } & \multicolumn{3}{|c|}{} \\
\cline { 2 - 8 } & HMA & JMF & OGFC & SMA & SCRB & OGFC & SMA \\
\hline $\mathbf{3 / 4 "}$ & 100 & 100 & 100 & 100 & 100 & 100 & 100 \\
\hline $\mathbf{1 / 2 "}$ & 95 & 96 & 92.5 & 90.5 & $90-100$ & $85-100$ & $90-100$ \\
\hline $\mathbf{3 / 8 "}$ & 83 & $* 90$ & 47.5 & 64 & $76-90$ & $35-60$ & $50-80$ \\
\hline No. 4 & 59 & $* 63$ & 17.5 & 28 & $44-74$ & $10-25$ & $20-35$ \\
\hline No. 8 & 43 & $* 38$ & 7.3 & 17.5 & $28-58$ & $5-10$ & $16-24$ \\
\hline No. 50 & 13 & 13 & - & - & $5-21$ & - & - \\
\hline No. 200 & 7 & 5 & 3 & 10.5 & $4-10$ & $2-4$ & $8-11$ \\
\hline
\end{tabular}

TABLE VI. SELECTED AGGREGATE GRADATION AND LIMITING VALUE FOR EME

\begin{tabular}{|c|c|c|c|c|c|c|}
\hline $\begin{array}{c}\text { Test sieve } \\
\text { opening }\end{array}$ & $\begin{array}{c}\text { EME } \\
0 / 14\end{array}$ & \multicolumn{2}{|c|}{ BBME 0/14 } & \multicolumn{3}{|c|}{$\operatorname{SCRB}(\mathrm{R} / \mathbf{9}, 2003)$} \\
\hline 31.5 & - & \multirow{2}{*}{$\begin{array}{c}\text { Sieve } \\
\text { size } \\
(\mathrm{mm}) \\
\end{array}$} & \multirow{2}{*}{$\begin{array}{c}\text { Specification } \\
\text { range }(\%)\end{array}$} & \multirow{2}{*}{$\begin{array}{c}\text { Standard } \\
\text { sieve } \\
(\mathrm{mm})\end{array}$} & \multicolumn{2}{|c|}{ Passing, \% } \\
\hline 20 & 100 & & & & $\begin{array}{l}\text { Specification } \\
\text { range }\end{array}$ & $\begin{array}{l}\text { Selected } \\
\text { gradation }\end{array}$ \\
\hline 14 & 90-99 & 20 & 100 & 19 & 100 & 100 \\
\hline 10 & - & 14 & $90-99$ & 12.5 & $90-100$ & 95 \\
\hline 6.3 & $42-65$ & 10 & - & 9.5 & $76-90$ & 83 \\
\hline 4 & - & 4 & - & 4.75 & $44-74$ & 50 \\
\hline 2 & $19-42$ & 2 & $19-42$ & 2.36 & $28-58$ & 40 \\
\hline 0.25 & $8-18$ & 0.25 & $8-18$ & 0.3 & $5-21$ & 13 \\
\hline 0.063 & $5-9$ & 0.063 & $5-9$ & 0.075 & $4-10$ & 7 \\
\hline
\end{tabular}

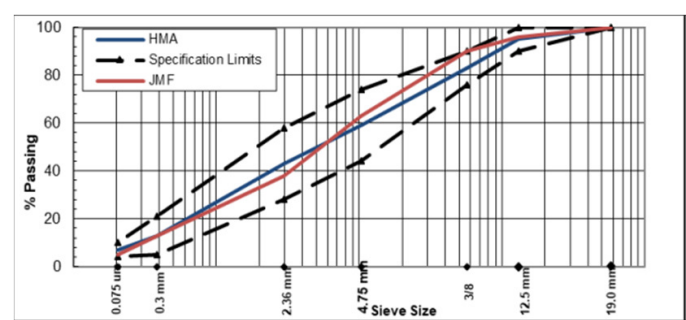

Fig. 1. Specification limits and selected gradation for HMA and JMF.



Fig. 2. Specification limits and selected gradation for OGFC.

\section{Mineral Filler}

Limestone dust from the lime factory in Karbala Governorate was used as the mineral filler. 


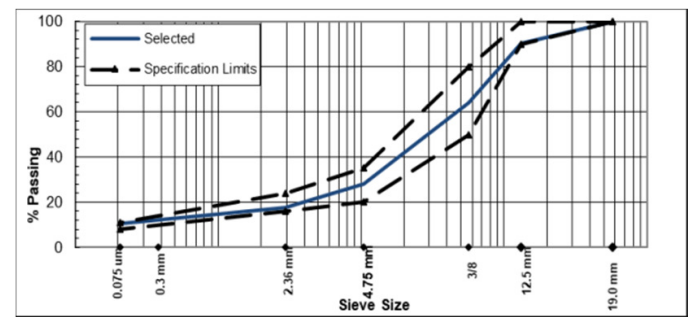

Fig. 3. Specification limits and selected gradation for SMA

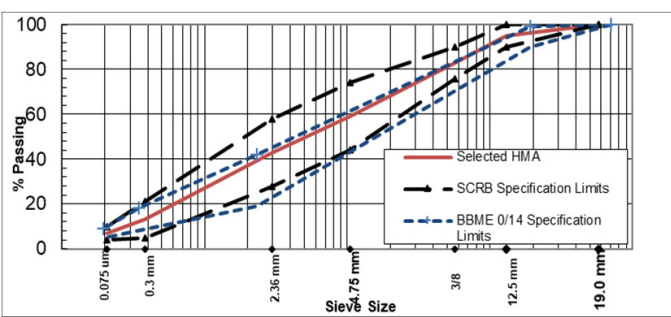

Fig. 4. Specification limits and selected gradation for EME.

\section{Additives}

CFs were used in this work. They were added at $0.3 \%$ by weight of mix and had $1.5 \mathrm{~cm}$ length. These fibers were obtained by using a paper shredder machine, as shown in Table VII [18].

TABLE VII. PHYSICAL CHARACTERISTICS OF CARBON FIBERS

\begin{tabular}{|c|c|}
\hline Test properties & Typical lalue \\
\hline Nominal thickness $(\mathrm{mm})$ & 0.167 \\
\hline Fiber length $(\mathrm{mm})$ & Can be produced at any length \\
\hline Color & 1.82 \\
\hline Density $\left(\mathrm{gm} / \mathrm{cm}^{3}\right)$ & 40000 \\
\hline Tensile strength $\left(\mathrm{N} / \mathrm{mm}^{2}\right)$ & 1.7 \\
\hline Elongation-at-break $(\%)$ & 225 \\
\hline Tensile modulus of elasticity $\left(\mathrm{kN} / \mathrm{mm}^{2}\right)$ & Polyacrylonitrile \\
\hline Base & $1400{ }^{\circ} \mathrm{C}$ \\
\hline Temperature of carbonization & \\
\hline
\end{tabular}

TABLE VIII. PHYSICAL CHARACTERISTICS OF SISAL FIBERS

\begin{tabular}{|c|c|}
\hline Test properties & Typical value \\
\hline Diameter $(\mathrm{mm})$ & 5 \\
\hline Fiber length $(\mathrm{cm})$ & $90-110$ \\
\hline Color & Natural white cream \\
\hline Density $\left(\mathrm{gm} / \mathrm{cm}^{3}\right)$ & 1.58 \\
\hline Tensile strength $\left(\mathrm{N} / \mathrm{mm}^{2}\right)$ & 385 to 728 \\
\hline Elongation-at-break $(\%)$ & 2.75 \\
\hline Young's modulus $(\mathrm{GPa})$ & $9-22$ \\
\hline Moisture & 6.55 \\
\hline Fire resistance & Good \\
\hline
\end{tabular}

TABLE IX. HYDRATED LIME PROPERTIES

\begin{tabular}{|c|c|}
\hline Property & Result \\
\hline Specific gravity & 2.43 \\
\hline Passing sieve No. 200 $(0.075 \mathrm{~mm})(\%)$ & 99 \\
\hline Specific surface area $\left(\mathrm{m}^{2} / \mathrm{kg}\right)$ & 395 \\
\hline
\end{tabular}

The second additive, SF is a performance leader among the most comprehensively used common fibers. Approximately 3.8 million tons of SFs are developed each year worldwide. They were added at $0.3 \%$ by weight of mix and had $0.5 \mathrm{~cm}$ length [21]. These fibers were obtained by using a paper shredder machine, as shown in Table VIII. Finally, HL is a promising material to be used in pavements due to its unique physical, chemical, and mechanical characteristics. It was used as an additive for asphalt mixtures (dry mix with aggregate) at a percentage of $1.5 \%$ by weight of aggregates [17]. The chemical and physical properties of HL (Figure 7) are listed in Table IX.
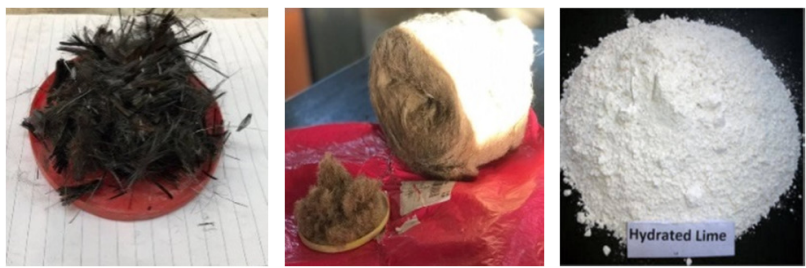

Fig. 5. Images of CF and SF after shredding and HL.

\section{SPECIMEN PREPARATION AND TESTING PROCEDURE}

The procedure covers preparation, compaction and testing of $101.6 \mathrm{~mm}$ (4in.) diameter and nominal $63.5 \mathrm{~mm}$ (2.5in.) height cylindrical specimens using the Marshall Apparatus in accordance with ASTM D 6926-04 [21]. Following this phase, the selected weight of asphalt binder was heated to the temperature that produces a kinematic viscosity of $170 \pm 20$ centistokes (i.e. $150^{\circ} \mathrm{C}$ ) and was mixed thoroughly with preheated aggregates for two minutes. To complete the molding process, the compaction procedure was conducted at temperature that produces an asphalt binder kinematic viscosity of $280 \pm 30$ centistokes (i.e. $140^{\circ} \mathrm{C}$ ). For each specimen, Marshall stability and flow tests were performed. The cylindrical specimens were placed in a water bath at $60^{\circ} \mathrm{C}$ for 30 minutes and then they were compressed on the lateral surface at a constant rate of $50.8 \mathrm{~mm} / \mathrm{min}(2 \mathrm{in} / \mathrm{min})$ until failure. The maximum load resistance and the corresponding flow value were recorded, and the average results were reported. Figure 6 shows the preparation of the specimens.

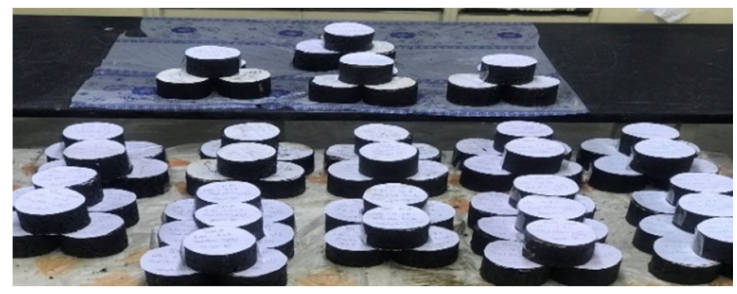

Fig. 6. Marshall specimens.

Repeated Load - Permanent Deformation testing was applied to the Marshall specimens and the resilient vertical strain was computed under load repetitions via a Pneumatic Repeated Load System (PRLS). Diametric loading was conducted to a steady loading rate of 60 cycles per minute, and the loading system for every cycle consisted of a $0.1 \mathrm{~s}$ load duration and $0.9 \mathrm{~s}$ rest period to simulate the testing conditions clarified in [23]. The mix and testing variables were:

- Test temperature: Two levels of temperature, 40 and $60^{\circ} \mathrm{C}$, are used.

- Stress: $137.9 \mathrm{kPa}$ (20 psi) stress was selected as target. 
- Asphalt Grade: AC type 40-50 and type 20-30 were used. The procedure of the test can be summarized as follows:

- Place the specimens in the room of testing for two hours at $40^{\circ} \mathrm{C}$ and $60^{\circ} \mathrm{C}$ to achieve the test temperature and permit uniform temperature spreading in the specimens.

- Position the LVDT on the specimen and connect it to a PC, as shown in Figure 10.

- The pressure actuator is set. The control of both the rest and loading ports is also set to the preferred load and the duration of rest after the end of the sample "setup".

- Start the repeated load test until 10,000 cycles are reached or the specimen fails.

The results of rutting tests in terms of permanent strain ( $\varepsilon p)$ are plotted against the number of repetitions by (1) for each specimen to find plastic parameters, the intercept (a) and the slope (b). These parameters can be estimated from (1) [5]:

$$
\varepsilon \mathrm{p}=\mathrm{aN}^{\mathrm{b}}
$$

The intercept (a) represents the permanent strain at a number of load repetitions (N) equal to one, while slope (b) represents the rate of change in the permanent strain as a function of the change in loading cycles $(\mathrm{N})$ on the log-log scale. Once the regression coefficients have been calculated, the permanent deformation coefficients alpha $(\alpha)$ and mu $(\mu)$ are computed using the relationship given in (2) and (3) [5]:

$$
\begin{gathered}
\alpha=1-b \\
\mu=(a-b) / \varepsilon r
\end{gathered}
$$

where $\varepsilon r$ is the resilient microstrain, $\varepsilon p$ the plastic microstrain, $\mathrm{mu}(\mu)$ is the permanent deformation parameter representing the constant proportionally between permanent strain and resilient strain (i.e. plastic strain at $\mathrm{N}=1$ ), and alpha $(\alpha)$ is a permanent deformation parameter indicating the rate of decrease in incremental permanent deformation as the number of load applications increases.

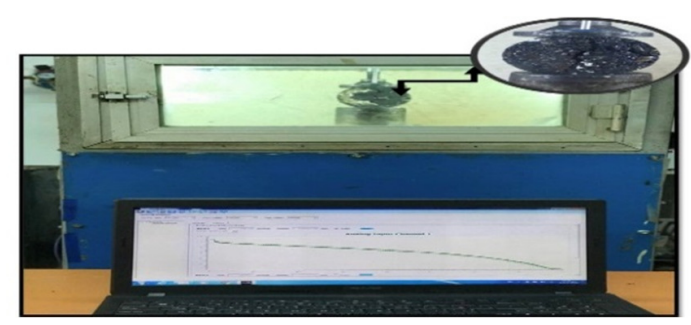

Fig. 7. Repeated load system.

For each mixture, 6 samples were used ( 3 samples for each temperature) to evaluate the permanent deformation. The analysis of the results is based on the temperature and mixture type under constant stress and constant time of loading $(0.1 \mathrm{~s}$ loading, 0.9s unloading) as showing in Figure 7.

\section{PAVEMENT PERFORMANCE EVALUATION}

To reduce the risk of unsatisfactory pavement performance to an acceptable level, engineers must be able to reliably predict pavement behavior over time. In this study, VESYS 5W software is used to predict the pavement performance. VESYS $5 \mathrm{~W}$ has been successfully used to analyze the asphalt pavement performance under field traffic and under accelerated pavement testing loads. A period of 15 years is considered in the analysis. VESYS $5 \mathrm{~W}$ needs to be provided with parameters in form of input data to run the analysis. These input parameters include the material properties of the layers, thickness, traffic data, and environmental conditions. The VESYS analysis procedure uses advanced mechanistic concepts to predict the behavior and performance of flexible pavements. Strain and deflection responses are computed and then used in conjunction with the failure criteria to predict pavement distress in terms of cracking, rutting, and roughness. Distress is used to define pavement performance in terms of the life history of the Present Serviceability Index (PSI). All the components of the design procedure have been formulated to take into account the inherent variability in traffic estimates, material properties, environmental conditions, and in the many construction practices used (VESYS 5W user Manual 2003) [24].

\section{RESULTS AND DISSCUSSION}

\section{A. Marshall Stability and Flow}

The results show that in the case of HMA, a greater increase in stability is observed by adding filler than by adding fibers (of both types) for the same asphalt content. An increase in stability of up to $12.5 \%$ is observed when using natural fibers (SF) compared to using CF, but the increase reaches $25 \%$ in the case of using HL compared to SF with an increase in asphalt content. The mineral filler effect on the asphalt indicates that lime substantially increases the viscosity (stiffness) of AC binders. The increase in viscosity of the asphalt binder also increases the resistance to water as shown in Figure 8.

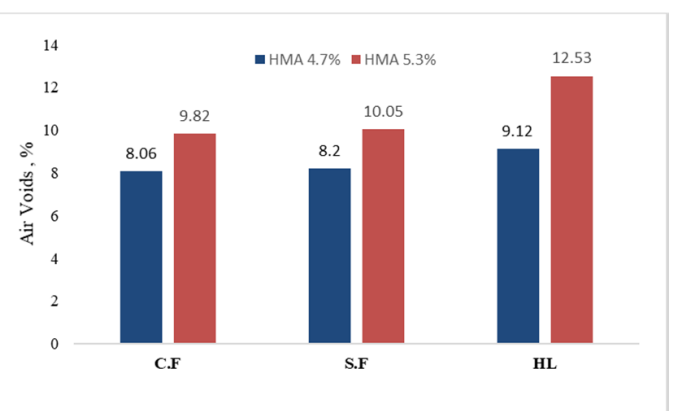

Fig. 8. HMA stability by changing the asphalt content for each type of additive.

In the case of SMA, as shown in Figure 9, the opposite is observed: the stability increases by adding fibers (of both types) more than by adding fillers (HL). An increase in stability of up to $16 \%$ occurred when using CFs compared to using HL, which reaches $24.2 \%$ when using SFs compared to $\mathrm{CF}$. Because the strength of SMA relies mostly on the stone-onstone aggregate skeleton, the fibers must be designed to mix and be placed with a strong coarse aggregate skeleton that provides the desired strength and stability to the mix more than fillers. 


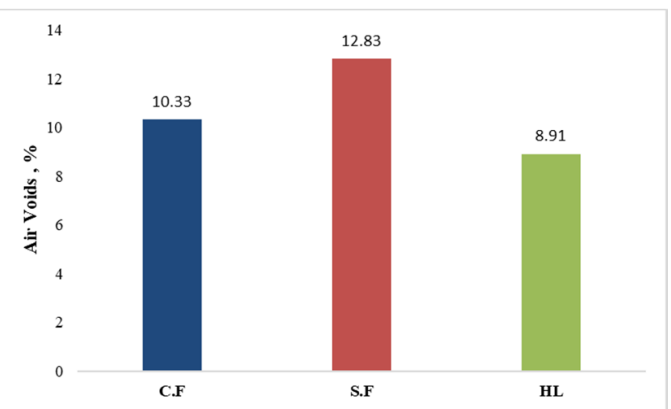

Fig. 9. Increasing stability of SMA by changing the type of additives.

After choosing HMA (5.3\% asphalt content with HL) and SMA (with SF), as the best choices from the previous mixtures, the remaining mixtures are discussed and compared with the control mixture (Figure 10). It is noted that the EME mixture has a high stability value (increased by $56.8 \%$ ) compared to the conventional (control) mixture and others because it increases binder stiffness and consequently the value of Marshall stability. Regardless of the above, the JMF achieves high stability without increasing the optimum asphalt content or additives (by 90.7\% compared to the control mixture), because the aggregate gradation with low maximum aggregate size achieves higher stability values against that of the common high maximum size gradations and enhances the performance of asphalt mixtures, crack resistance in particular. In addition, the increasing stability values may be due to the increase in workability and the easiness of compaction and the best interlock in particular.

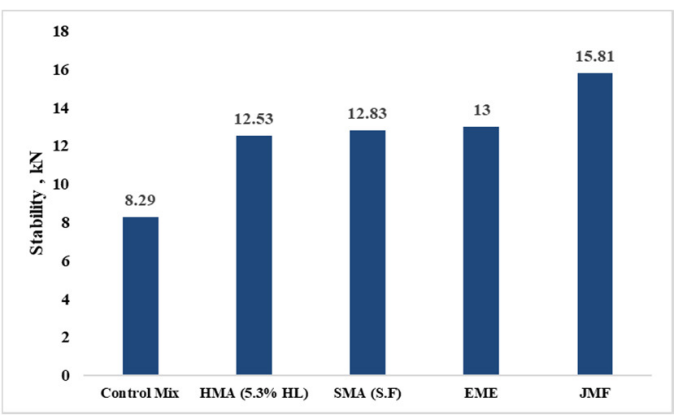

Fig. 10. Comparison of changes in the stability of the mixtures.

TABLE $X$. MARSHALL STABILITY AND FLOW RESULTS.

\begin{tabular}{|c|c|c|c|c|}
\hline Mix type & $\begin{array}{c}\text { Asphalt } \\
\text { Content } \\
(\%) \\
\end{array}$ & Modifier type & $\begin{array}{c}\text { Stability } \\
(\mathbf{k N})\end{array}$ & $\begin{array}{l}\text { Flow } \\
(\mathrm{mm})\end{array}$ \\
\hline Control mix & \multirow{2}{*}{4.7} & \multirow{2}{*}{ Without additives } & 8.29 & 3.2 \\
\hline EME & & & 13 & 3.3 \\
\hline \multirow{6}{*}{ HMA } & \multirow{3}{*}{4.7} & $\mathrm{CF}$ & 8.06 & 3.8 \\
\hline & & SF & 8.2 & 3.2 \\
\hline & & $\mathrm{HL}$ & 9.12 & 2.3 \\
\hline & \multirow{3}{*}{5.3} & $\mathrm{CF}$ & 9.82 & 2.5 \\
\hline & & SF & 10.05 & 3.4 \\
\hline & & $\mathrm{HL}$ & 12.53 & 2.7 \\
\hline \multirow{3}{*}{ SMA } & \multirow{3}{*}{5.3} & $\mathrm{CF}$ & 10.33 & 2.6 \\
\hline & & SF & 12.83 & 2.9 \\
\hline & & $\mathrm{HL}$ & 8.91 & 4.01 \\
\hline JMF & 4.7 & Without additives & 15.81 & 3.3 \\
\hline
\end{tabular}

The Marshall stability test results are listed in Table X. The results indicate that the increase and decrease in the Marshall flow is related to the type and content of the additive, as well as to the type of mixture. When flow values are examined, it is observed that high flow values are usually related to plastic mixtures subject to permanent deformations. However, flow values are measured between the required specification ranges of 2 to $4 \mathrm{~mm}$.

\section{B. Suggested Performance Tests for OGFC}

In the case of an OGFC mixture, two tests instead of the Marshall test are suggested to evaluate its performance. As shown in Figures 11 and 12, for both tests, the highest value of air voids $(\% \mathrm{AV})$ appears for the mixture containing the filler HL (30\%) and the worst result in the draindown test compared to the mixture with $\mathrm{CF}$, while the mixture containing SF gives the desired result in the draindown test and acceptable air voids (10\%) compared to the mixture with CF because the natural fiber gives the best stability and the most homogeneous distribution inside the OGFC mixture.

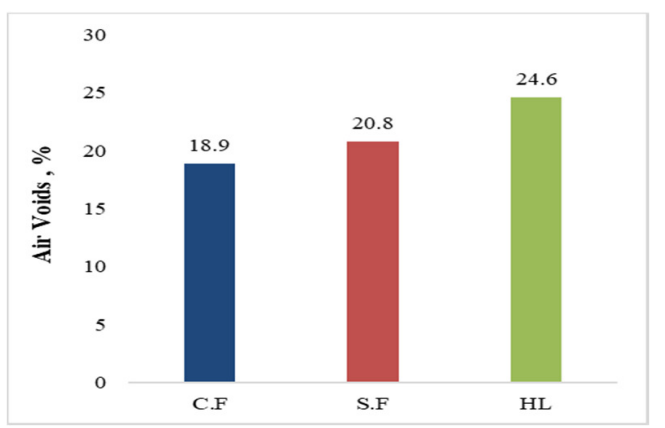

Fig. 11. Comparison of air void test result.

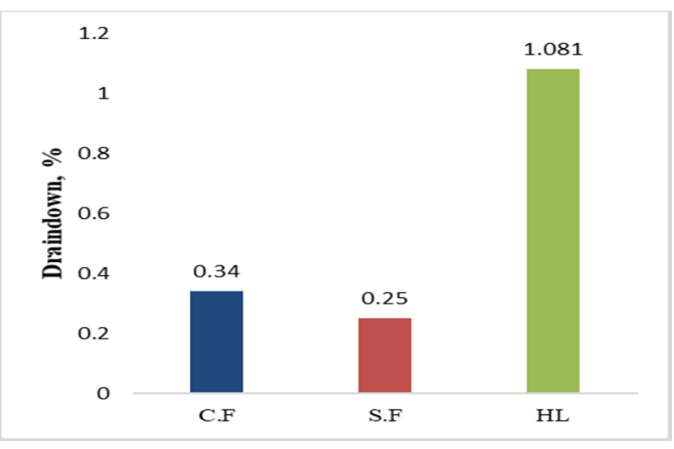

Fig. 12. Comparison of draindown test result.

\section{PAVEMENT PERFORMANCE EVALUATION}

All the components of the design procedure were formulated to take into account the inherent variability in traffic estimates, material properties, environmental conditions and the many forms of construction practices used.

- Pavement structure: The geometry of the pavement structure is shown in Figure 13. The structure is a conventional flexible pavement section with 5 layers: wearing course, binder (leveling) course, base course, subbase course, and subgrade. 


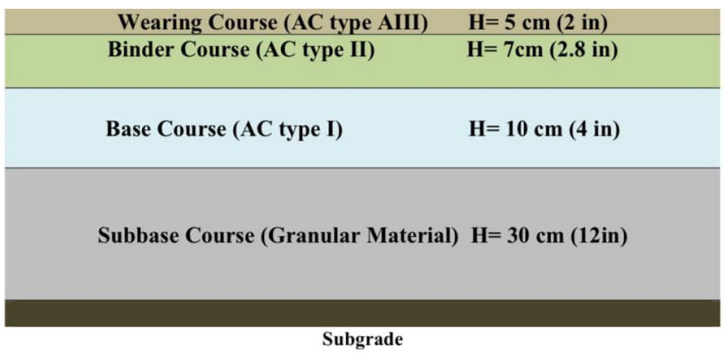

Fig. 13. Geometry of the pavement structure.



Fig. 14. Eighteen-kip ESAL configuration.

- Temperature: The assumed Mean Air Pavement Temperature (MAPT) is $40^{\circ} \mathrm{C}$. Such a temperature is expected to occur in the middle of the $\mathrm{AC}$ pavement layer during the hot summer seasons in Iraq.

- Material Properties: When the pavement structure is treated as a multilayer elastic system, it is necessary to quantify the material stiffness properties. These properties are needed for the calculation of the stresses, strains and deflection response in the pavement system under the application of traffic loading. The parameters $(\alpha$ and $\mu)$ shown in Tables XI-XIII are calculated from the repeated load test that was performed on the asphalt mixtures, and are used as input into the VESYS $5 \mathrm{~W}$ to estimate the rut depth of a selected pavement structure using the properties of different asphalt mixtures. Alpha $(\alpha)$ and mu $(\mu)$ parameters for binder, base and subbase courses are taken as default values, while the corresponding value for the wearing course varies according to the laboratory test results.

TABLE XI. PLASTIC PARAMETERS FOR MIXTURES WITH $4.7 \%$ AC

\begin{tabular}{|c|c|c|c|c|c|c|}
\hline \multicolumn{7}{|c|}{ Selected asphalt content (4.7\%) @ 40 ${ }^{\circ} \mathbf{C}$} \\
\hline $\begin{array}{c}\text { Mix } \\
\text { type }\end{array}$ & $\begin{array}{c}\text { Control } \\
\text { mix }\end{array}$ & $\begin{array}{c}\text { Control } \\
\text { mix } \\
\text { CF }\end{array}$ & $\begin{array}{c}\text { Control } \\
\text { mix } \\
\text { SF }\end{array}$ & $\begin{array}{c}\text { Control } \\
\text { mix } \\
\text { HL }\end{array}$ & EME & JMF \\
\hline$\alpha$ & 0.378 & 0.409 & 0.485 & 0.502 & 0.706 & 0.810 \\
\hline$\mu$ & 0.189 & 0.205 & 0.243 & 0.252 & 0.353 & 0.403 \\
\hline \multicolumn{7}{|c|}{ Selected asphalt content (4.7\%) @ $\mathbf{6 0}^{\circ} \mathbf{C}$} \\
\hline$\alpha$ & 0.302 & 0.244 & 0.253 & 0.345 & 0.506 & 0.746 \\
\hline$\mu$ & 0.151 & 0.122 & 0.127 & 0.173 & 0.253 & 0.373 \\
\hline
\end{tabular}

- Traffic loading: Low traffic loading is used in this study. The low-volume road category is defined by AASHTO as roads that carry significant levels of truck traffic, and the maximum number of 18kips $(80 \mathrm{kN})$ is shown in Figure 14. The Equivalent Single Axle Load (ESAL) applications considered for flexible and rigid pavement design are 7000,000 over 15 years. In this study, 1 million ESAL applications are used for the design life. The annual growth rate is assumed to be $5 \%$.

TABLE XII. PLASTIC PARAMETERS FOR MIXTURES WITH 5.3\% AC

\begin{tabular}{|c|c|c|c|c|c|c|}
\hline \multicolumn{7}{|c|}{ Selected asphalt content (5.3\%) @ $\mathbf{4 0}^{\circ} \mathbf{C}$} \\
\hline $\begin{array}{c}\text { Mix } \\
\text { type }\end{array}$ & $\begin{array}{c}\text { HMA } \\
\text { CF }\end{array}$ & $\begin{array}{c}\text { HMA } \\
\text { SF }\end{array}$ & $\begin{array}{c}\text { HMA } \\
\text { HL }\end{array}$ & $\begin{array}{c}\text { SMA } \\
\text { CF }\end{array}$ & $\begin{array}{c}\text { SMA } \\
\text { SF }\end{array}$ & $\begin{array}{c}\text { SMA } \\
\text { HL }\end{array}$ \\
\hline$\alpha$ & 0.402 & 0.474 & 0.642 & 0.442 & 0.632 & 0.234 \\
\hline$\mu$ & 0.201 & 0.237 & 0.321 & 0.221 & 0.316 & 0.117 \\
\hline \multicolumn{7}{|c|}{ Selected asphalt content (5.3\%) @ $\mathbf{6 0}{ }^{\circ} \mathbf{C}$} \\
\hline$\alpha$ & 0.325 & 0.362 & 0.503 & 0.344 & 0.404 & 0.126 \\
\hline$\mu$ & 0.163 & 0.181 & 0.252 & 0.172 & 0.202 & 0.063 \\
\hline
\end{tabular}

TABLE XIII. PLASTIC PARAMETERS FOR MIXTURES WITH $6 \%$ AC

\begin{tabular}{|c|c|c|c|}
\hline \multicolumn{4}{|c|}{ Selected asphalt content $(6 \%) @ 40{ }^{\circ} \mathrm{C}$} \\
\hline $\begin{array}{l}\text { Mix } \\
\text { type }\end{array}$ & $\begin{array}{c}\text { OGFC } \\
\text { CF }\end{array}$ & $\begin{array}{c}\text { OGFC } \\
\text { SF }\end{array}$ & $\begin{array}{c}\text { OGFC } \\
\text { HL }\end{array}$ \\
\hline$\alpha$ & 0.376 & 0.405 & 0.286 \\
\hline$\mu$ & 0.188 & 0.203 & 0.143 \\
\hline \multicolumn{4}{|c|}{ Selected asphalt content $(6 \%) @ 60^{\circ} \mathrm{C}$} \\
\hline$\alpha$ & 0.251 & 0.290 & 0.102 \\
\hline$\mu$ & 0.126 & 0.145 & 0.051 \\
\hline
\end{tabular}

\section{RESULTS OF THE VESYS 5W RUN}

By using VESYS $5 \mathrm{~W}$, the permanent deformation result was estimated as a rut depth in mm plus the PSI. Rut depth less than $12.5 \mathrm{~mm}$ is the desired criteria that be maintained over a service life of 15 years, as suggested in [27].

\section{A. HMA $(4.7 \%)$}

As shown in Figures 15 and 16, additives may improve the performance of the mixture, but only if they are suitable for grading the mixture and containing the appropriate asphalt content, e.g. the mixture with the HL reduces rut depth more than the mixture with SF and CF. At 7 million ESALs and $40^{\circ} \mathrm{C}$, the rut depth for mixtures with $\mathrm{HL}, \mathrm{SF}$, and $\mathrm{CF}$ is 7.8 , 9.56 , and $18.64 \mathrm{~mm}$ respectively, which shows that the addition of HL improves the mechanical behavior by increasing the stability of the mixture at relatively high temperatures $\left(40^{\circ} \mathrm{C}\right.$ and $60^{\circ} \mathrm{C}$ ). The $\mathrm{HL}$ content displays an effective influence, particularly at $40^{\circ} \mathrm{C}$. The HL filler actually stiffens the asphalt film and reinforces it. Furthermore, lime makes HMA less sensitive to moisture by improving the aggregate-asphalt bond. This synergistically improves rut resistance [28].

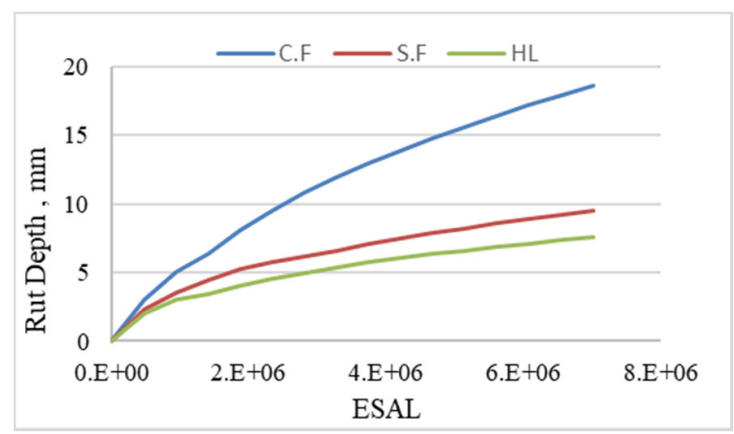

Fig. 15. Rut depth of $\operatorname{HMA}(4.7 \%)$ at $40^{\circ} \mathrm{C}$ 


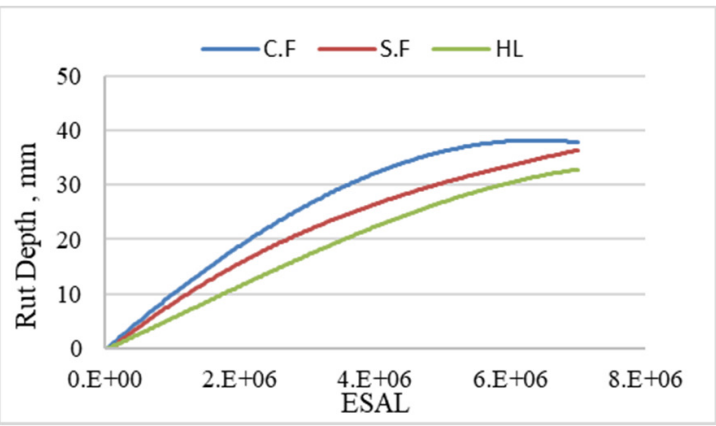

Fig. 16. Rut depth of $\operatorname{HMA}(4.7 \%)$ at $60^{\circ} \mathrm{C}$

\section{B. $H M A(5.3 \%)$}

Figures 17 and 18 show that increasing the asphalt content leads to a reduction in the rut depth under the same ESALs at two test temperatures, for every mixture and every type of modifier. The rut depth for the HL, SF, and CF mixtures are $3.18,8.72$ and $17.45 \mathrm{~mm}$ respectively at 7 million ESALs and $40^{\circ} \mathrm{C}$. This improvement is probably due to the well-distributed additives, in different directions of the bituminous matrix, which are highly resistant to shear displacement and strongly prevent any movement of the aggregate particles, therefore increasing the rutting resistance of the mixture [29, 43]. From the above, the best option for the HMA-type mixture with the additive for both asphalt contents is HMA (5.3\%) with HL.

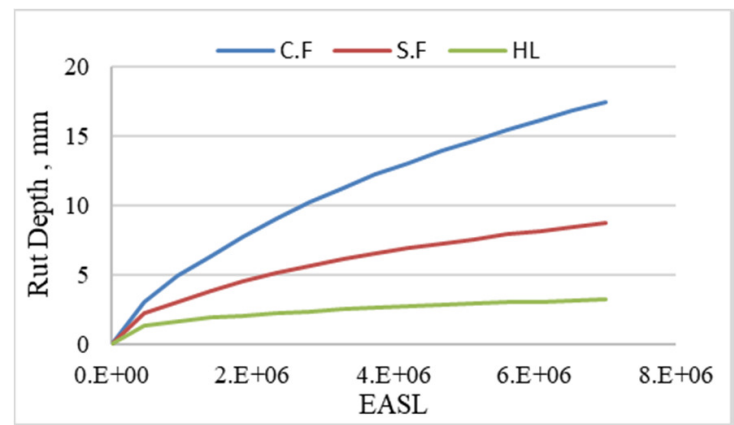

Fig. 17. Rut depth of $\operatorname{HMA}(5.3 \%)$ at $40^{\circ} \mathrm{C}$.

\section{SMA}

Figures 19 and 20 show the effect of different mixture types (changing gradation) on the rut depth. Such mixtures need to be modified for draindown.

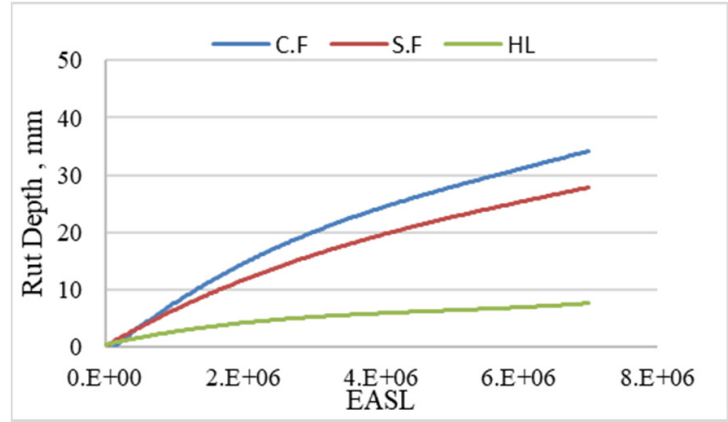

Fig. 18. Rut depth of $\operatorname{HMA}(5.3 \%)$ at $60^{\circ} \mathrm{C}$.

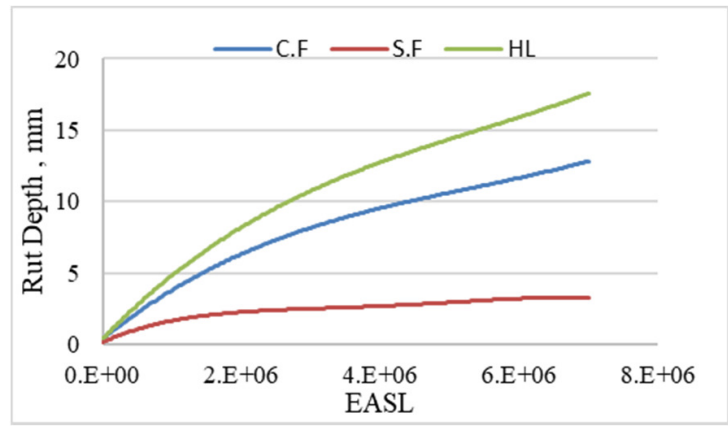

Fig. 19. Rut depth of SMA $(5.3 \%)$ at $60^{\circ} \mathrm{C}$.

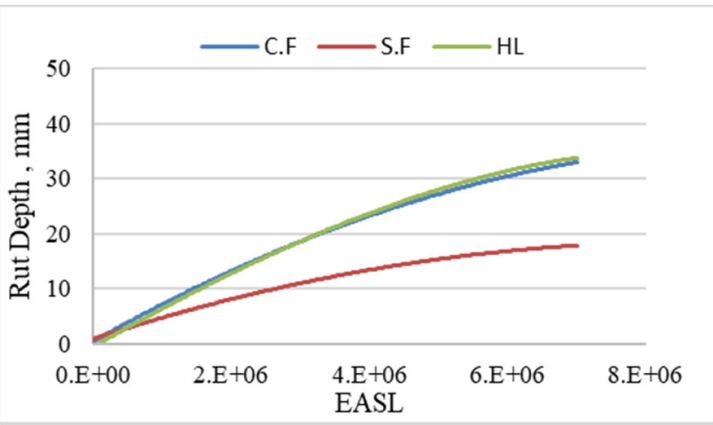

Fig. 20. Rut depth of SMA (5.3\%) at $60^{\circ} \mathrm{C}$.

It is noted that the mixture of SMA with fibers gives a better result compared with HL filler. On the other hand, the natural SF performs better inside the SMA mixture than the $\mathrm{CF}$. For example, at $7000000 \mathrm{ESALs}$ and $40^{\circ} \mathrm{C}$, it is noted that the rut depth in mixtures with $\mathrm{SF}, \mathrm{CF}$, and $\mathrm{HL}$ is $3.33,12.72$, and $17.45 \mathrm{~mm}$ respectively.

\section{D. $O G F C$}

Similar to the previous mixture, the mixture containing fibers (SF and CF) gives a better result compared to the mixture with filler (HL). However, this mixture has less resistance than SMA under high temperatures and heavy ESAL. For example, it is noted that the mixture with SF exceeds the permissible limit of rutting as for 3.7 million ESALs under the temperature of $40^{\circ} \mathrm{C}$ it was $12.63 \mathrm{~mm}$ and with CF $16.39 \mathrm{~mm}$, as shown in Figures 21 and 2. It is noted that both stone matrix asphalt (SMA) and OGFC with fibers are used as stabilizers. Fibers decrease the drainage of the mix and increase the resistance more than hydrated lime.

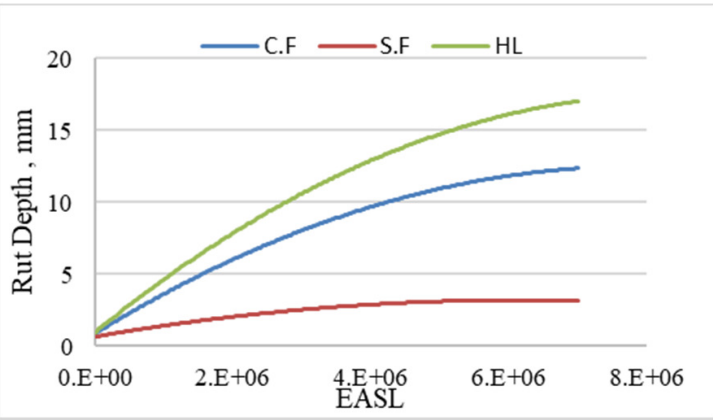

Fig. 21. Rut depth of OGFC $40^{\circ} \mathrm{C}$. 


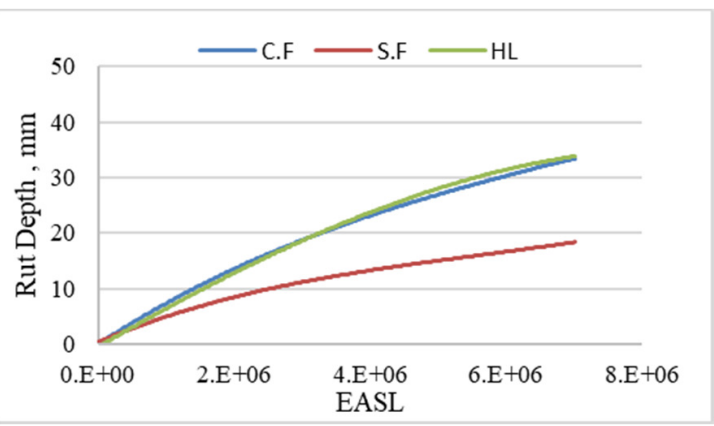

Fig. 22. Rut depth of OGFC $40^{\circ} \mathrm{C}$.

\section{E. Conventional (Control) Mixture}

As seen from Figures 23-26, maximum rut depth occurs in conventional mixtures when higher temperatures and higher stresses are applied. The asphalt mixture becomes softer with increasing temperature, which leads to more permanent deformation at the same stress. Increasing stress has a negative effect on the pavement structure and increases the movement of pavement particles, leading to large rutting at the same temperature [30]. After selecting the mixtures with the highest rutting resistance from the above, they are compared with the control mixture (Figures 23-26). At 7000000 ESALs and $40^{\circ} \mathrm{C}$, it is noted that the rut depth decreases by $20.48 \mathrm{~mm}$ when using HMA $5.3 \%$ (HL) and by $20.33 \mathrm{~mm}$ when using SMA (SF).

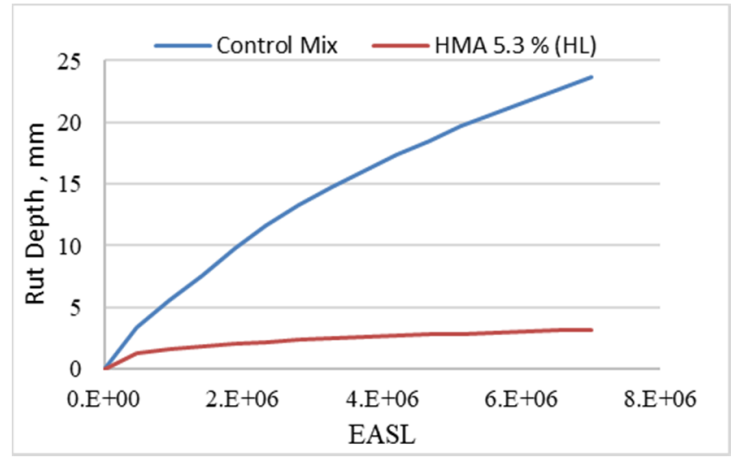

Fig. 23. Rutting depth for HMA 5.3\% (HL) and conventional mix at $40^{\circ} \mathrm{C}$.

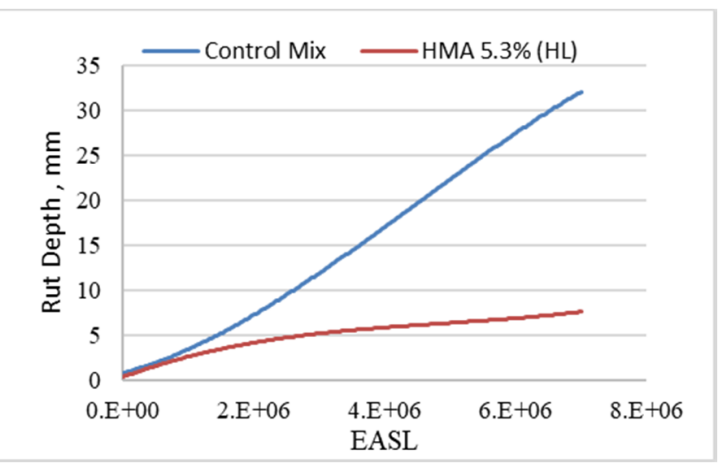

Fig. 24. Rutting depth for HMA 5.3\% (HL) and conventional mix at $60^{\circ} \mathrm{C}$.

\section{F. $B B M E$}

Figures 27 and 28 illustrate the effect of high modulus and conventional mixture on the rutting depth of the pavement geometry. It can be seen that at the 15 th year after 7,0000,0000 ESALs at $40^{\circ} \mathrm{C}$ and $60^{\circ} \mathrm{C}$, the BBME mixture exhibits lower rut depths of 21.14 and $25.33 \mathrm{~mm}$ respectively, than the conventional mixture. Therefore, the stiff binder improves the pavement performance susceptibility to permanent deformation failures during hot summers and repeated loads $[31,36]$.

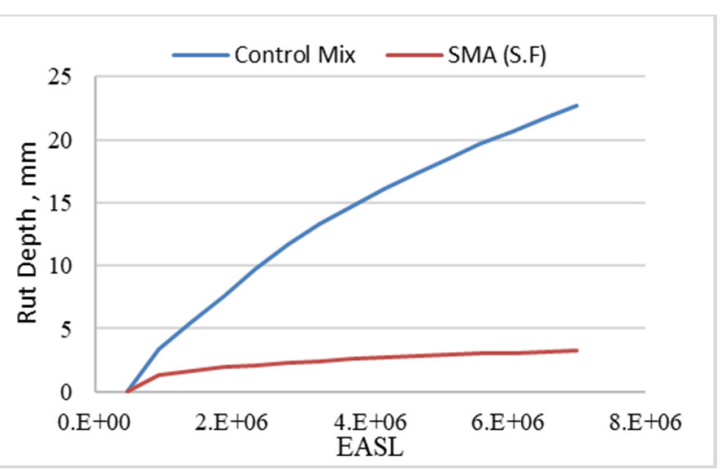

Fig. 25. Rut depth for SMA with SF and conventional mix at $40^{\circ} \mathrm{C}$

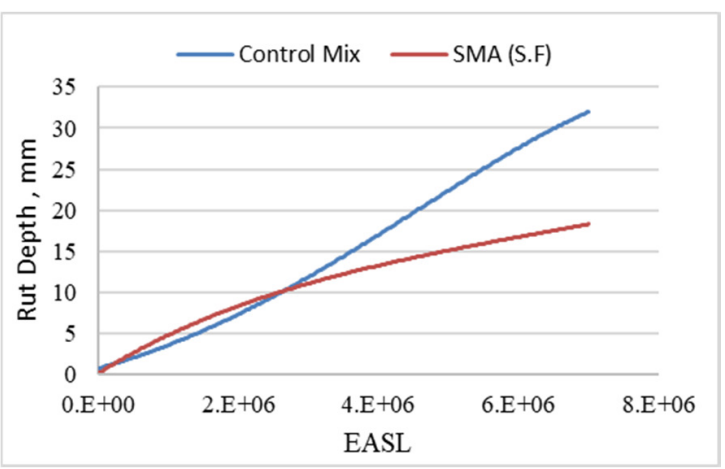

Fig. 26. Rut depth for SMA with SF and conventional mix at $60^{\circ} \mathrm{C}$.

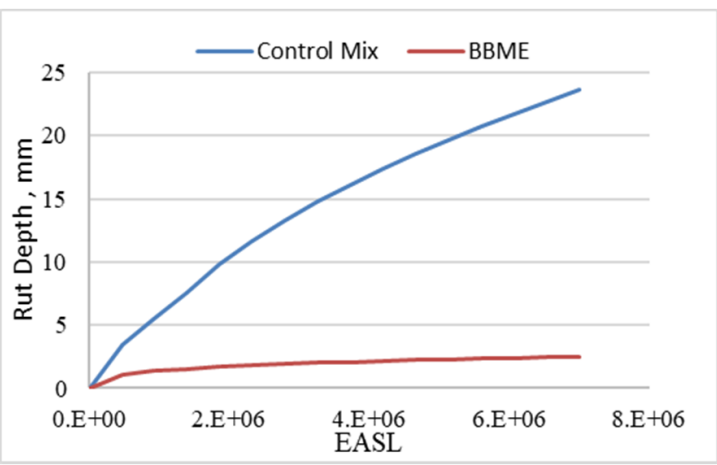

Fig. 27. Rutting depth for BBME and conventional mix at $40^{\circ} \mathrm{C}$.

\section{G. Dense Gradation Mix (JMF)}

Finally, the JMF gives the best rutting resistance results. It can be seen that after 15 years and 7,0000,0000 ESALs at $40^{\circ} \mathrm{C}$ and $60^{\circ} \mathrm{C}$, the JMF mixture exhibits lower rut depths by 21.63 and $30.4 \mathrm{~mm}$ than the control mixture, as shown in Figures 29 and 30 , because the addition of fine aggregates strongly increases the friction within the mixture. In addition, angular aggregates are known to have more resistance to rutting than other configurations [32]. Additionally, the aggregates form the 
internal structure of the asphalt mixture and are responsible for its strength and durability in carrying loads and mixing the internal bonds that help resist deformations [33].

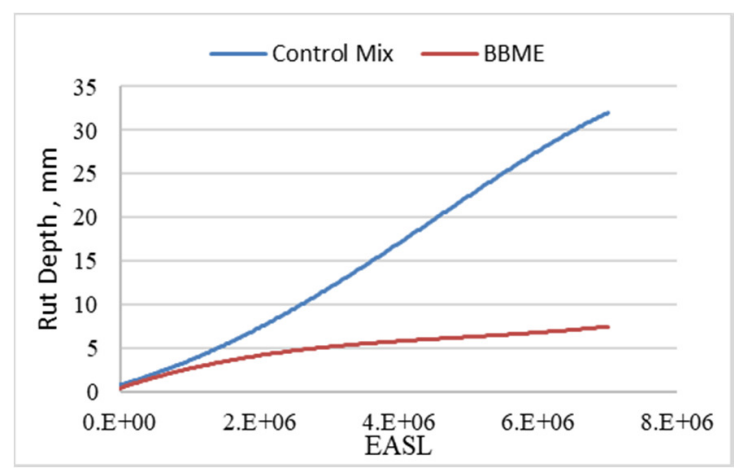

Fig. 28. Rutting depth for BBME and conventional mix at $60^{\circ} \mathrm{C}$.

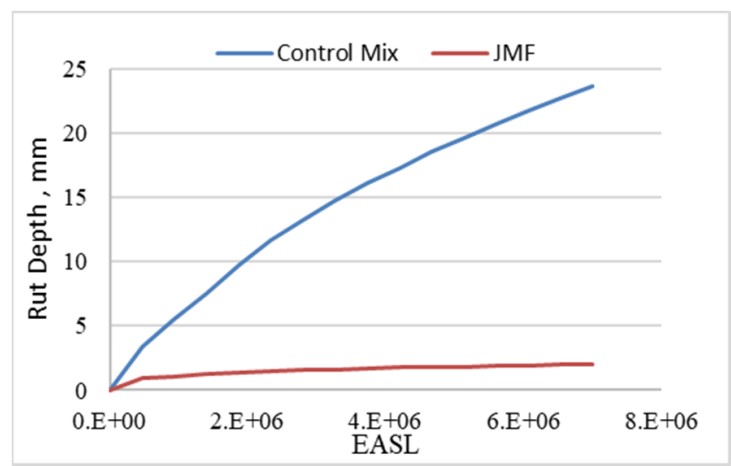

Fig. 29. Rutting depth for JMF and conventional mixture at $40^{\circ} \mathrm{C}$.

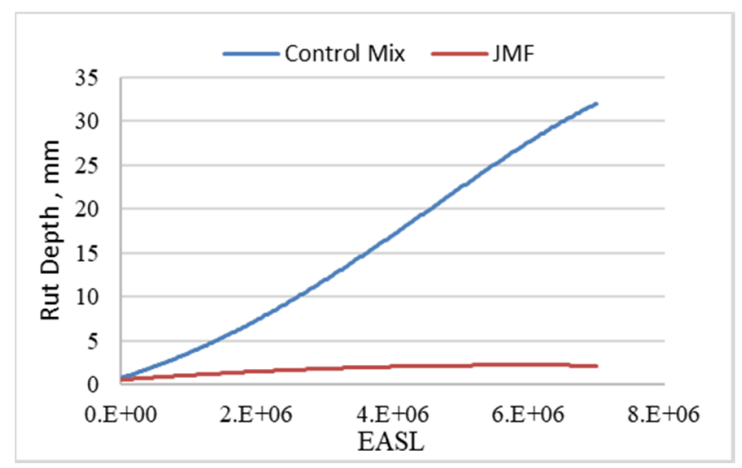

Fig. 30. Rutting depth for JMF and conventional mixture at $60^{\circ} \mathrm{C}$.

Based on the previous results, it is concluded that the strongest and most resistant to rusting under high load and high temperatures are the JMF and the BBME mixtures. However, attention should be given to an important point regarding the BBME mixture, as it may not be used in practice as a surface layer except in rare cases, due to the fact that it may be prone to thermal cracking and fatigue cracking and it may not provide a surface texture with sufficient skid resistance.

When multiple layers of EME are constructed, it is crucially important that good bonding between the two courses is achieved [33, 35]. Therefore, the choice of type depends on the conditions and specifications determined by the requirements, its efficiency in solving the desired problem, and its effectiveness over the years, which altogether achieve the lowest cost and good performance. In this study, the change in aggregate gradations within the permissible limits of the local mixture used currently in Iraq without additives or changing the content of asphalt is the most efficient in resisting the high temperatures prevailing in Iraq and the least expensive with a high rutting resistance (which is the common deformation mode in the country) and other deformation performance, as shown by the results.

\section{CONCLUSIONS}

Based on the test results, the optimal mixture for this study is JMF with $4.7 \%$ binder content. When flow values were examined, it was observed that high flow values are usually related to plastic mixtures subject to permanent deformations. The performance of the HMA mixture can be improved by using additives, and it was found that the use of HL as a filler gives better results than the use of fibers, and by increasing the asphalt content from $4.7 \%$ to $5.3 \%$ for the same mixture gradation, stability and rutting resistance increase. The main outcomes of this study are:

- The addition of HL improves the mechanical behavior by increasing the stability of the mixture at relatively high temperatures.

- Marshall stability increased by $10 \%$ in HMA (4.7\%) with HL and by $51 \%$ in HMA $(5.3 \%)$ with HL in comparison with the control mixture, but regarding rutting resistance, the HMA $(5.3 \%)$ mixture with HL was more resistant than the HMA $(4.7 \%)$ mixture with HL under high temperatures and heavy load.

- It was concluded that the best additive is usually the fibers, especially the natural SFs. Fibers have been used in a global scale for many decades to reinforce paving materials. A very common use of fibers is to add them into open graded mixtures or porous asphalt to avoid draining down bitumen from aggregates. However, the use of fibers in dense graded mixtures to increase stability or improve cracking resistance is less common.

- SF has good elasticity due to its high moisture absorption capability and because it acts as a reinforcement inside both mixtures. The stability was $12.83 \mathrm{kN}$ and the flow was $2.9 \mathrm{~mm}$ in the case of SMA (SF), while the draindown was $0.25 \%$ and the percentage of air voids was $20.8 \%$ in the case of OGFC (SF). Regarding rutting resistance, the SMA mixture was more resistant than the OGFC mixture under high temperatures and heavy load.

- It was noted that BBME gave good Marshall stability and flow values that were greater than those of the conventional mixture by $58.6 \%$ and $3.1 \%$ respectively. It also exhibited and high resistance to permanent deformation. It was noted that the BBME gave good resistance to deformation values because a stiffer asphalt binder plays a role in rutting resistance at high temperatures.

- Finally, the JMF gave the best and highest results in Marshall stability and flow, which were increased by $90.7 \%$ 
and $3.1 \%$, respectively, and also high rutting resistance by decreasing the rut depth by $21.63 \mathrm{~mm}$ in comparison with the conventional mix under 7000000 ESALs and $40^{\circ} \mathrm{C}$ after 15 years of operation because the addition of fine aggregates increases the friction within the mixture. The permanent deformation parameters alpha and mu are more sensitive to temperature and stress level than the other parameters considered in this research. The test results show the difference in shape between conventional (40-50) and stiff $(20-30)$ binders at $40^{\circ} \mathrm{C}$ and $60^{\circ} \mathrm{C}$. This means that the BBME mixture has excellent resistance to permanent deformation (rutting) and a high effect on alpha and mu.

- The effect of the gradient on the plastic parameters (alpha and $\mathrm{mu}$ ) is very high and clear by comparing the mixtures, where the aggregates are the main element in the strength of the mixture and the appropriate gradation in the extent of its durability and resistance to deformation. The JMF mixture gave the highest values of alpha and mu.

\section{REFERENCES}

[1] W. H. Goetz, J. F. McLaughlin, and L. E. Wood, Load Deformation Characteristics of Bituminous Mixtures Under Various Conditions of Loading. West Lafayette, Indiana: Purdue University, 1957.

[2] A. Albayati, "Permanent Deformation Prediction of Asphalt Concrete under Repeated Loading," Ph.D. dissertation, University of Baghdad, Baghdad, Iraq, 2006.

[3] HMA Pavement Mix Type Selection Guide. Washington, DC, USA: National Asphalt Pavement Association and Federal Highways Administration, 2001.

[4] P. Chaturabong and H. U. Bahia, "The evaluation of relative effect of moisture in Hamburg wheel tracking test," Construction and Building Materials, vol. 153, pp. 337-345, Oct. 2017, https://doi.org/10.1016/ j.conbuildmat.2017.07.133.

[5] E. R. Brown and S. A. Cross, A national study of rutting in hot mix asphalt (HMA) pavements. Alabama, USA: Auburn University, 1992.

[6] U. Ghani, A. Iqbal, S. Ullah, M. Rizwan, and M. Javed, "Comparison of Rutting Resistance of Stone Mastic Asphalt with Convention Mix," United International Journal for Research \& Technology, vol. 1, no. 11, pp. 22-28, 2020.

[7] G. A. W. Majeed and S. I. Sarsam, "Assessing the Marshall Properties of Porous Asphalt Concrete," Journal of Engineering, vol. 27, no. 3, pp. 113-129, Feb. 2021, https://doi.org/10.31026/j.eng.2021.03.08.

[8] T. Baghaee Moghaddam, M. Soltani, and M. R. Karim, "Experimental characterization of rutting performance of Polyethylene Terephthalate modified asphalt mixtures under static and dynamic loads," Construction and Building Materials, vol. 65, pp. 487-494, Aug. 2014, https://doi.org/ 10.1016/j.conbuildmat.2014.05.006.

[9] A. Mahrez, M. R. Karim, and H. Y. bt Katman, "Fatigue and Deformation Properties of Glass Fiber Reinforced Bituminous Mixes," Journal of the Eastern Asia Society for Transportation Studies, vol. 6, pp. 997-1007, 2005, https://doi.org/10.11175/easts.6.997.

[10] D. N. Little, P. E. Sebaaly, and P. E. Sebaaly, Hydrated lime in hot mix asphalt. Texas, USA: National Lime Association, 2006.

[11] M. A. Notani, A. Arabzadeh, H. Ceylan, S. Kim, and K. Gopalakrishnan, "Effect of Carbon-Fiber Properties on Volumetrics and Ohmic Heating of Electrically Conductive Asphalt Concrete," Journal of Materials in Civil Engineering, vol. 31, no. 9, Sep. 2019, Art. no. 04019200, https://doi.org/10.1061/(ASCE)MT.1943-5533.0002868.

[12] S. Karahancer, E. Eriskin, M. Saltan, S. Terzi, O. Sarioglu, and D. O. Kucukcapraz, "Investigating The Utility Of Sisal In Hot Mix Asphalt As A Fiber," Muhendislik Bilimleri ve Tasarım Dergisi, vol. 7, no. 4, pp. 906-912, Dec. 2019, https://doi.org/10.21923/jesd.553502.

[13] K. Kanitpong, T. J. Atud, and W. Martono, "Application Process of Hydrated Lime to Resist Moisture Damage and Rutting in a Phalt
Mixture and Revision Report," Journal of the Eastern Asia Society for Transportation Studies, vol. 7, pp. 2051-2061, 2007, https://doi.org/ 10.11175/easts.7.2051.

[14] A. H. K. Albayati and A. M. Mohammed, "Effect of Lime Addition Methods on Performance Related Properties of Asphalt Concrete Mixture," Journal of Engineering, vol. 22, no. 9, pp. 1-20, Sep. 2016.

[15] NF P98-141: Enrobés Hydrocarbonés - Couches De Roulement Et Couches De Liaison: Bétons Bitumineux À Module Élevé (Bbme) Définition - Classification - Caractéristiques - Fabrication - Mise en Oeuvre. Paris, France: AFNOR, 1999.

[16] Standard Specification for Roads and Bridges. Nepal: Ministry of Physical Infrastructure and Transport, Department of Roads.

[17] ASTM D7064/D7064M-21(2005), Standard Practice for Open-Graded Friction Course (OGFC) Asphalt Mixture Design. West Conshohocken, PA, USA: ASTM International, 2005.

[18] AASHTO (2012), Standard Specifications for Transportation Materials and Methods of Sampling and Testing, 32nd Edition. Washington, DC, USA: American Association of State Highway and Transportation Officials, 2012.

[19] P. J. Sanders and M. Nunn, The application of Enrobe a Module Eleve in flexible pavements. Berkshire, England: Transport Research Laboratory, 2005.

[20] M. Razahi and A. Chopra, "A Review Of Using Ssisal Fiber And Coir Fiber As Additives In Stone Matrix Asphalt," International Research Journal of Engineering and Technology, vol. 7, no. 2, pp. 1692-1697, Jul. 2020.

[21] ASTM D6926-04(2010), Standard Practice for Preparation of Bituminous Specimens Using Marshall Apparatus. West Conshohocken, PA, USA: ASTM International, 2010.

[22] E. J. Yoder and M. W. Witczak, Principles of Pavement Design. New York, NY, USA: John Wiley \& Sons, 1991.

[23] "Truck Pavement Interaction Program," in VESYS 5Ws User Manual, 2003.

[24] ASTM D6390(2011), Standard Test Method for Determination of Draindown Characteristics in Uncompacted Asphalt Mixtures. West Conshohocken, PA, USA: ASTM International, 2011.

[25] ASTM E2018-15(2017), Standard Guide for Property Condition Assessments: Baseline Property Condition Assessment Process. West Conshohocken, PA, USA: ASTM International, 2017.

[26] F. Zhou, T. Scullion, and D.-H. Chen, "Laboratory Characterization of Asphalt Mixes of SPS-1 Sections on US281," Road Materials and Pavement Design, vol. 3, no. 4, pp. 439-453, Jan. 2002, https://doi.org/ 10.1080/14680629.2002.9689935.

[27] F. F. Al-khafaji, "The Effect of Combination and Addition of Some Mineral Fillers on Hot Mix Asphalt Performance," Journal of University of Babylon, vol. 23, no. 2, pp. 336-347, 2015.

[28] O. M. Kunene and D. Allopi, "Comparison Between Conditions of Major Roads Within and Outside the Port of Durban," Engineering, Technology \& Applied Science Research, vol. 3, no. 1, pp. 363-367, Feb. 2013, https://doi.org/10.48084/etasr.263.

[29] S. Oda, J. Leomar Fernandes, and J. S. Ildefonso, "Analysis of use of natural fibers and asphalt rubber binder in discontinuous asphalt mixtures," Construction and Building Materials, vol. 26, no. 1, pp. 1320, Jan. 2012, https://doi.org/10.1016/j.conbuildmat.2011.06.030.

[30] H. Mohammed Mahan, "Behavior of permanent deformation in asphalt concrete pavements under temperature variation," Al-Qadisiyah Journal for Engineering Sciences, vol. 6, no. 1, pp. 62-73, Mar. 2013.

[31] A. Pandian, M. Vairavan, W. J T, and M. Uthayakumar, "Effect of Moisture Absorption Behavior on Mechanical Properties of Basalt Fibre Reinforced Polymer Matrix Composites," Journal of Composites, vol. 2014, Mar. 2014, Art. no. 587980, https://doi.org/10.1155/2014/587980.

[32] T. Baghaee Moghaddam, "Development Of High Modulus Asphalt Concrete Mix Desing Technology For Use On Ontario's Highways," Ph.D. dissertation, University of Waterloo, Ontario, Canada, 2019.

[33] Y. Du, J. Chen, Z. Han, and W. Liu, "A review on solutions for improving rutting resistance of asphalt pavement and test methods," 
Construction and Building Materials, vol. 168, pp. 893-905, Apr. 2018, https://doi.org/10.1016/j.conbuildmat.2018.02.151.

[34] A. Golalipour, E. Jamshidi, Y. Niazi, Z. Afsharikia, and M. Khadem, "Effect of Aggregate Gradation on Rutting of Asphalt Pavements," Procedia - Social and Behavioral Sciences, vol. 53, pp. 440-449, Oct. 2012, https://doi.org/10.1016/j.sbspro.2012.09.895.

[35] M. A. Rizvi, A. H. Khan, Z. ur Rehman, Z. Masoud, and A. Inam, "Effect of Fractured Aggregate Particles on Linear Stress Ratio of Aggregate and Resilience Properties of Asphalt Mixes-A Way Forward for Sustainable Pavements," Sustainability, vol. 13, no. 15, Jan. 2021, Art. no. 8630, https://doi.org/10.3390/su13158630.

[36] F. Alzaidy and A. H. K. Albayati, "A Comparison between Static and Repeated Load Test to Predict Asphalt Concrete Rut Depth," Engineering, Technology \& Applied Science Research, vol. 11, no. 4, pp. 7363-7369, Aug. 2021, https://doi.org/10.48084/etasr.4236.

[37] F. Najm and N. Y. Ahmed, "Evaluation the Using of Local Aggregate in High Modulus Asphalt Concrete Layers," Civil and Environmental Research, vol. 8, no. 3, pp. 28-41, 2016.

[38] M. Q. Ismael and R. F. A. Al-Harjan, "Evaluation of Job-Mix Formula Tolerances as Related to Asphalt Mixtures Properties," Journal of Engineering, vol. 24, no. 5, pp. 124-144, May 2018, https://doi.org/ 10.31026/j.eng.2018.05.09.

[39] A. Aljubory, Z. T. Teama, H. T. Salman, and H. M. Abd Alkareem, "Effects of cellulose fibers on the properties of asphalt mixtures," Materials Today: Proceedings, vol. 42, pp. 2941-2947, Jan. 2021, https://doi.org/10.1016/j.matpr.2020.12.772.

[40] M. Razahi and A. Chopra, "An Experimental Investigation of Using Sisal Fiber and Coir Fiber as An Additive in Stone Matrix Asphalt," International Journal of Advance Science and Technology, vol. 29, no. 10S, pp. 5111-5128, Jan. 2020.

[41] SCRB Standard Specification for Roads and Bridges (Section R/9). Baghdad, Iraq: State Commission of Roads and Bridges, Ministry of Housing and Construction, 2003.

[42] M. K. Shahad, "Assessment of the Durability of Stone Matrix Asphalt Concrete," M.S. thesis, University of Baghdad, Baghdad, Iraq, 2015.

[43] K. Jadidi, M. Khalili, M. Karakouzian, and S. Amirkhanian, "Toughness, Tenacity and Maximum Initial Strength of Rubber Modified Asphalt Binders," Engineering, Technology \& Applied Science Research, vol. 9, no. 1, pp. 3765-3769, Feb. 2019, https://doi.org/10.48084/etasr.2526. 